\title{
Reduction of nitrobenzene catalyzed by carbon materials
}

\author{
Shuchang Wu a,b, Guodong Wen a, Bingwei Zhong a, Bingsen Zhang a, Xianmo Gu a, Ning Wangc, \\ Dangsheng Su ${ }^{a, *}$ \\ a Shenyang National Laboratory for Materials Science, Institute of Metal Research, Chinese Academy of Sciences, Shenyang 110016, Liaoning, China \\ b Graduate University of Chinese Academy of Sciences, Beijing 100049, China \\ c Department of Physics, The Hong Kong University of Science and Technology, Hong Kong, China
}

\section{A R T I C L E I N F O}

Article history:

Received 15 March 2014

Accepted 27 March 2014

Published 20 June 2014

\section{Keywords:}

Carbon materials

Oxygenated groups

Active sites

Nitrobenzene

Reduction

\begin{abstract}
A B S T R A C T
The reduction of nitrobenzene catalyzed by different carbon materials (mainly carbon nanotubes) was studied. TGA, TPD, TEM, $\mathrm{N}_{2}$ adsorption-desorption, and Raman spectroscopy were used to show that it was oxygenated groups that gave catalytic activity, while the surface area, pore structure, morphology, structural defects and Fe impurities in the catalysts did not have a significant influence on the activity. The carbonyl group played an important role, but the carboxylic group and anhydride adversely affected the reaction. The conjugated $\pi$ system, which was necessary for electron transfer and nitrobenzene adsorption, was another critical factor. The reaction proceeded through the direct route in which the intermediate nitrosobenzene was converted directly to aniline quickly.
\end{abstract}

(C) 2014, Dalian Institute of Chemical Physics, Chinese Academy of Sciences. Published by Elsevier B.V. All rights reserved.

\section{Introduction}

The selective reduction of nitroarenes is an important process because aromatic amines are used in producing agrochemicals, pharmaceuticals, dyes and pigments, to name just a few of their applications [1-3] and continuous efforts have been devoted to developing efficient production techniques. Since the traditional non-catalytic methods that use either the $\mathrm{Fe} / \mathrm{HCl}$ system (Bechamp procedure) or metal sulfides inevitably generate large amounts of wastes [3], green and environmentally friendly selective reduction routes are urgently sought. Various kinds of noble metals [4-7] such as Au, Pd, Pt, and $\mathrm{Ru}$ have been reported to be highly effective catalysts. However, the high price and scarcity of these precious metals are main drawbacks that hindered their large scale industrial application. Besides, these metals are sensitive to air and moisture when they are in metal complex forms [8]. As an alternative, a number of cost-effective metals [9-11] including $\mathrm{Fe}, \mathrm{Ni}$ and $\mathrm{Cu}$ are attracting increasing attention, but their metal and metal oxide nanoparticles often have issues such as agglomeration that lead to deactivation.

The direct use of carbon materials as the catalyst is an interesting topic attracting more attention. Carbon, especially nanocarbons, can be used as an efficient catalyst for many gas phase and liquid phase reactions [12-17]. As a matter of fact, carbon is also active in the reduction of nitrobenzene [18-21]. One major problem with carbon-catalyzed reactions is that the activity may be due to metal impurities that remained in the carbon materials. However, we have found that nitrobenzene reduction can proceed without a metal catalyst by using model

\footnotetext{
* Corresponding author. Tel: +86-24-23971577; Fax: +86-24-83970019; E-mail: dssu@imr.ac.cn

This work was supported by the National Basic Research Program of China (973 Program, 2011CBA00504), the National Natural Science Foundation of China (21133010, 51221264, 21261160487, 21203215), "Strategic Priority Research Program" of the Chinese Academy of Sciences (XDA09030103), and the Doctoral Starting up Foundation of Liaoning Province, China (20121068).

DOI: 10.1016/S1872-2067(14)60102-9 | http://www.sciencedirect.com/science/journal/18722067 | Chin. J. Catal., Vol. 35, No. 6, June 2014
} 
catalysts [22]. Here, we studied systematically the reduction of nitrobenzene catalyzed by carbon materials, mainly carbon nanotubes (CNTs) and found that carbon indeed was an efficient catalyst for this reaction. The carbonyl group was one important active site, while the carboxylic and anhydride groups played an adverse role. The operating conditions and reaction pathway were also studied.

\section{Experimental}

\subsection{Chemicals}

The CNTs were bought from CNano Technology Ltd. (Flotube 9000). Graphite flake, nitrobenzene (99\%), azoxybenzene (98\%), azobenzene (97\%), and hydrazobenzene (90\%) were purchased from Alfa Aesar. Hydroxylamine (97\%) and nitrosobenzene (97\%) were obtained from Sigma-Aldrich. Granular activated carbon and hydrazine monohydrate were supplied by China Medicine Group Shanghai Chemical Reagent Company. Nanodiamond synthesized by the detonation method followed by acid washing was bought from Beijing Grish Hitech Co. (China). All reagents except the carbon catalysts were used without further purification.

\subsection{Preparation of carbon materials}

The CNTs were treated with concentrated $\mathrm{HCl}$ (rCNT) before use. Then, $\mathrm{rCNT}$ was dispersed in concentrated $\mathrm{HNO}_{3}$ and treated at $120^{\circ} \mathrm{C}$ (temperature of the oil bath) for $2 \mathrm{~h}$ after ultrasonication. After filtration and washing with distilled water, the oCNT obtained was dried at $110{ }^{\circ} \mathrm{C}$. For the thermal treatment, aliquots of oCNTs were calcined in a quartz tube under flowing helium at the set temperature for $2 \mathrm{~h}$, and the samples were cooled under helium to room temperature. The annealed samples were designated as oCNT- $X(X$ was the annealing temperature).

Graphite oxide (GO) was synthesized by Hummers' method with some modification [23]. Concentrated $\mathrm{H}_{2} \mathrm{SO}_{4}(230 \mathrm{~mL})$ was added to a mixture containing graphite flakes $(10.0 \mathrm{~g})$ and $\mathrm{NaNO}_{3}$ (5.0 g). The mixture was stirred by a mechanical agitator in an ice bath. Next, $\mathrm{KMnO}_{4}$ (30 g) was added to the slurry within $1 \mathrm{~h}$. After $2 \mathrm{~h}$, the mixture was heated to $35^{\circ} \mathrm{C}$, and kept for another $2 \mathrm{~h}$, followed by the slow addition of deionized water $(500 \mathrm{~mL})$. Subsequently, the slurry was heated to $90{ }^{\circ} \mathrm{C}$. After $40 \mathrm{~min}, \mathrm{H}_{2} \mathrm{O}_{2}$ (30\%) was dropped into the mixture until its color turned to light yellow. Finally, the product was washed first with $\mathrm{HCl}(2 \mathrm{~mol} / \mathrm{L})$, and then deionized water. The GO obtained was dried in an oven at $60^{\circ} \mathrm{C}$.

Graphene was prepared using the method in a previous report [24]. GO (1.0 g) was dispersed in $600 \mathrm{~mL}$ of deionized water. After $5 \mathrm{~mL}$ of ammonia was added, the mixture was ultrasonicated for $2 \mathrm{~h}$. Then $4 \mathrm{~mL}$ of hydrazine monohydrate (85\%) was added, and the flask that contained the solution was immersed in an oil bath at $90{ }^{\circ} \mathrm{C}$ for $4 \mathrm{~h}$. The solution was filtrated and the product reduced graphene oxide (RGO) was washed with water, followed by drying in an oven at $60^{\circ} \mathrm{C}$. In addition, graphene was also prepared by the thermal exfoliation method.
Typically, $1.0 \mathrm{~g}$ of GO was heated quickly $\left(15^{\circ} \mathrm{C} / \mathrm{min}\right)$ to a set temperature and kept for $2 \mathrm{~h}$, followed by cooling to room temperature under a noble gas.

\subsection{Sample characterization}

The morphology of samples was observed by transmission electron microscope (TEM, Tecnai G2 F20). Thermogravimetric analysis (TGA) was performed on a NETZSCH STA 449 F3 apparatus under argon flow (50 $\mathrm{mL} / \mathrm{min}$ ) with a heating rate of $10{ }^{\circ} \mathrm{C} / \mathrm{min}$ from 35 to $950{ }^{\circ} \mathrm{C}$. The specific surface area was measured by the BET method using nitrogen adsorption isotherms obtained on a Micrometrics ASAP 2020 system. Pore size distributions were estimated from the desorption branch of the isotherm using the $\mathrm{BJH}$ method. The total pore volume $\left(V_{t}\right)$ was estimated from the amount adsorbed at the relative pressure of 0.988 . Raman spectroscopy was performed by a LabRam HR 800 using 633 nm laser.

\subsection{Catalytic test}

Nitrobenzene reduction was studied using the above materials as catalyst with hydrazine monohydrate as the reducing reagent. Typically, a set amount of catalyst, $1.2 \mathrm{~g}$ of nitrobenzene and 6.0 equivalent of hydrazine monohydrate were added into a $25 \mathrm{ml}$ round-bottom flask. The mixture was heated in an oil bath for a set period of time using a water-cooled condenser. When the reaction was completed, a methanol/water (volume ratio $75: 25$ ) solution was added and the mixture was diluted to exactly $50 \mathrm{~mL}$ in a volumetric flask. The products were analyzed by HPLC (Elite, UV detector, mobile phase: 75/25 ( $\mathrm{v} / \mathrm{v}$ ) methanol/water) with a SinoChrom ODS-BP column. Unless otherwise noted, the reaction temperature was the temperature of the oil bath.

\section{Results and discussion}

\subsection{Catalytic performance of oCNT under different conditions}

We firstly used oCNT as an example to evaluate the catalytic activity of carbon materials for nitrobenzene reduction. The conversion was quite low without a catalyst, but it increased notably to $43.9 \%$ when only $2 \mathrm{mg}$ of oCNT was added, indicating the crucial role of the catalyst (Table 1). The conversion increased as more catalyst was added from 2 to $20 \mathrm{mg}$, but a

\section{Table 1}

Effect of catalyst loading on nitrobenzene reduction.

\begin{tabular}{lcc}
\hline Catalyst loading $(\mathrm{mg})$ & $X$ (Nitrobenzene)/(\%) & $S($ Aniline $) /(\%)$ \\
\hline 0 & 21.8 & 98.8 \\
2 & 43.9 & 93.5 \\
8 & 69.4 & 96.7 \\
15 & 92.7 & 93.1 \\
20 & 97.2 & 95.2 \\
25 & 99.7 & 93.5 \\
\hline
\end{tabular}

Reaction conditions: a set amount of oCNT, $1.2 \mathrm{~g}$ of nitrobenzene, 6.0 equiv of hydrazine monohydrate, $100^{\circ} \mathrm{C}, 4 \mathrm{~h}$. 
Table 2

Reduction of nitrobenzene at different temperatures.

\begin{tabular}{lccc}
\hline Entry & Temperature $\left({ }^{\circ} \mathrm{C}\right)$ & $X$ (Nitrobenzene) $/ \%$ & $S$ (Aniline) $/ \%$ \\
\hline $1^{\mathrm{a}}$ & 110 & 99.9 & 95.6 \\
$2^{2}$ & 100 & 97.2 & 95.2 \\
$3^{\mathrm{b}}$ & 100 & 94.7 & 95.1 \\
$4^{\mathrm{a}}$ & 90 & 63.0 & 95.5 \\
$5^{6}$ & 80 & 33.9 & 98.8 \\
$6^{\mathrm{c}}$ & 80 & 74.2 & 96.6 \\
\hline
\end{tabular}

Reaction conditions: $20 \mathrm{mg}$ of oCNT, $1.2 \mathrm{~g}$ of nitrobenzene, 6.0 equivalent of hydrazine monohydrate, $4 \mathrm{~h}$.

${ }^{a}$ Reacted for $3 \mathrm{~h}$. ${ }^{\mathrm{b}}$ Under $\mathrm{N}_{2}$ atmosphere. ${ }^{\mathrm{c}}$ Reacted for $10 \mathrm{~h}$.

further increase of the catalyst loading had only a marginal effect on the activity under this condition.

The results illustrated in Table 2 showed that the temperature had a large effect on the reaction. Nearly all the nitrobenzene was converted at $110^{\circ} \mathrm{C}$ within $3 \mathrm{~h}$, but at least $4 \mathrm{~h}$ was needed to reach a similar conversion at $100{ }^{\circ} \mathrm{C}$. The reaction proceeded slowly at $80{ }^{\circ} \mathrm{C}$ : only $74.2 \%$ of nitrobenzene was reduced in $10 \mathrm{~h}$. Moreover, the reaction can proceed in nitrogen as well as in air (Table 2, entries 2 and 3).

The solvent is important in most organic reactions. We studied the effect of the solvent on the nitrobenzene reduction, and the results are summarized in Table 3. Dimethyl sulfoxide (DMSO) performed better than any other solvent for nitrobenzene conversion. Regardless of the solvent added (except water), the aniline selectivity always decreased concurrently with notable increases of azoxybenzene and azobenzene selectivities. For example, when $2 \mathrm{~mL}$ ethanol was added, the aniline selectivity decreased from $95.2 \%$ to $87.7 \%$.

After the first run, the oCNT was washed three times with methanol. Then the catalyst was reused for the next test. No obvious deactivation was observed even for the 8th run, suggesting good reproducibility and stability of oCNT in this reaction (Fig. 1).

\subsection{Reaction pathway}

The generally accepted reaction pathways for the reduction of nitrobenzene are the direct route and condensation route [25]. In the direct route, nitrobenzene is first reduced to nitro-
Table 3

Reduction of nitrobenzene in different solvents.

\begin{tabular}{|c|c|c|c|c|}
\hline \multirow{2}{*}{ Solvent } & \multirow{2}{*}{$X($ Nitrobenzene $) / \%$} & \multicolumn{3}{|c|}{$S / \%$} \\
\hline & & Aniline & AXB & $\mathrm{AB}$ \\
\hline Water & 45.7 & 96.9 & 2.5 & 0.6 \\
\hline Methanol & 84.1 & 83.2 & 2.7 & 10.1 \\
\hline Ethanol & 88.2 & 87.7 & 2.9 & 9.4 \\
\hline Isopropanol & 91.0 & 83.1 & 3.2 & 11.7 \\
\hline Dioxane & 77.8 & 84.0 & 6.3 & 5.9 \\
\hline Acetone & 61.1 & 67.4 & 7.3 & 9.1 \\
\hline Acetonitrile & 56.2 & 80.5 & 5.7 & 4.4 \\
\hline No & 97.2 & 95.2 & 0.9 & 3.7 \\
\hline Dimethyl Sulfoxide & 99.6 & 83.2 & 5.4 & 8.8 \\
\hline Dimethyl Sulfoxide ${ }^{A}$ & 85.2 & 86.5 & 4.9 & 9.8 \\
\hline
\end{tabular}

Reaction conditions: $20 \mathrm{mg}$ of oCNT, $1.2 \mathrm{~g}$ of nitrobenzene, 6.0 equivalent of hydrazine monohydrate, $2 \mathrm{~mL}$ of solvent, $100^{\circ} \mathrm{C}, 4 \mathrm{~h}^{\text {a }}{ }^{\text {Reacted }}$ at $90^{\circ} \mathrm{C}$. AXB-Azoxybenzene. AB-Azobenzene.

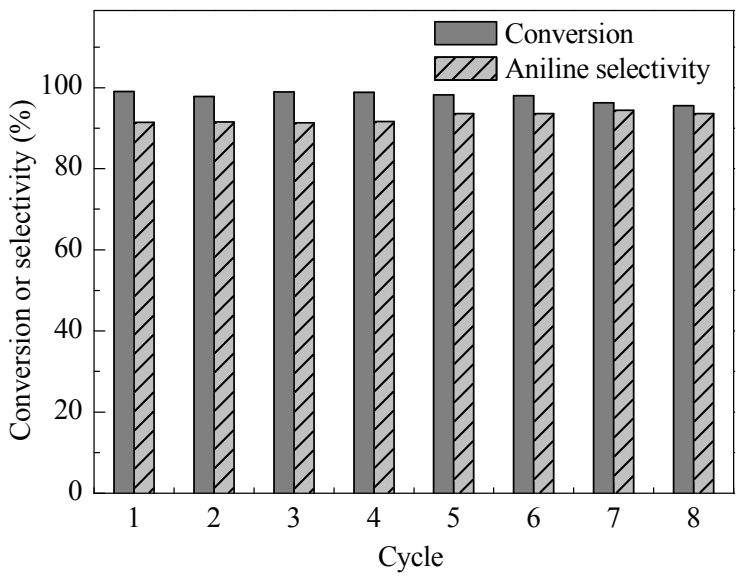

Fig. 1. Recycling test of oCNT. Reaction conditions: $20 \mathrm{mg}$ of oCNT, $1.2 \mathrm{~g}$ of nitrobenzene, 6.0 equivalent of hydrazine monohydrate, $100{ }^{\circ} \mathrm{C}, 4 \mathrm{~h}$. At the end of the reaction, the oCNT was rinsed with methanol and reused for the next run.

sobenzene, and then consecutively to hydroxylamine and aniline. In the condensation pathway, one molecule of nitrosobenzene reacts with an equivalent amount of hydroxylamine to form azoxybenzene, and then azoxybenzene is reduced to azobenzene, hydrazobenzene and aniline in turn (Scheme 1).

Aniline was the main product in the process (Fig. 2),<smiles>Nc1ccccc1CCc1ccccc1</smiles>

(1)<smiles>Cc1ccccc1[N+](=O)[O-]</smiles><smiles>[N-]=[N+]=[N+]=[N-]</smiles>

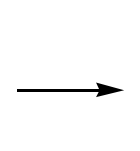

HDA
(2)<smiles>O=[N+]([O-])c1ccccc1-c1cccc(CC2CC3CCC2C3)c1</smiles><smiles>Nc1ccccc1</smiles><smiles>CCC=NO</smiles><smiles>CCN(c1ccccc1)c1ccccc1</smiles><smiles>Nc1ccccc1NNc1ccccc1</smiles>

AXB<smiles>C1CCC2(CC1)CCCC2</smiles>

$\mathrm{AB}$

$\mathrm{HAB}$

Scheme 1. Direct (1) and condensation (2) pathways for the reduction of nitrobenzene. 


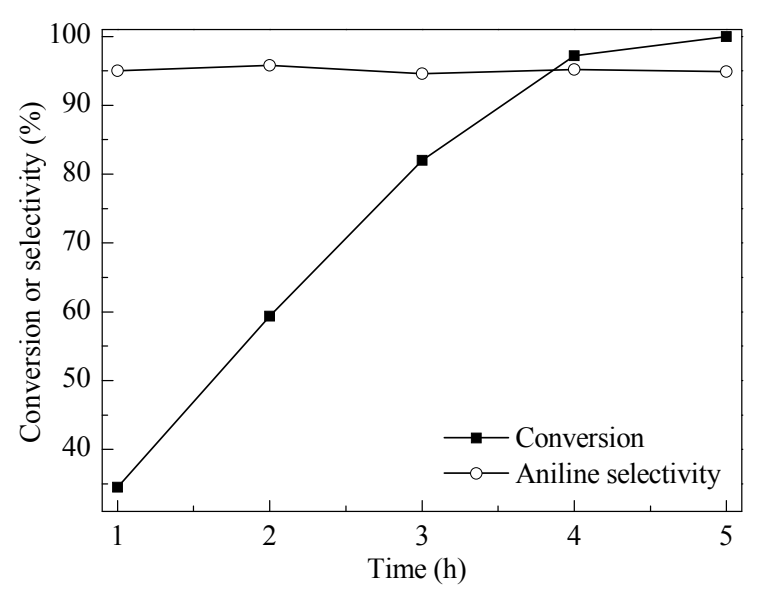

Fig. 2. Reduction of nitrobenzene in the presence of oCNT. Reaction condition: $20 \mathrm{mg}$ of oCNT, $1.2 \mathrm{~g}$ of nitrobenzene, 6.0 equivalent of hydrazine monohydrate, $100^{\circ} \mathrm{C}$.

suggesting its quick formation and high stability. The byproducts were azoxybenzene, azobenzene and hydrazobenzene, but these byproducts only accounted for a small portion (about 5\%). From Fig. 2, we could not determine which reaction pathway was responsible for this reaction. Azoxybenzene, azobenzene and hydrazobenzene are formed as intermediates in the condensation route. Therefore, we studied the conversion of these three compounds. All of these compounds could not be converted to aniline, and hydrazobenzene was the final product (Table 4, entries 1-4). In addition, a catalyst was necessary for the reduction of these substrates. When no oCNT was used, the conversion of azobenzene decreased sharply to $36.0 \%$ as compared to the catalytic process. We then tested the conversion of both nitrosobenzene and hydroxylamine. When the round-bottom flask containing oCNT, nitrosobenzene and hydrazine monohydrate was immersed into a $100{ }^{\circ} \mathrm{C}$ oil bath, a large amount of bubbles was formed immediately, indicating that the reaction proceeded violently. After $1 \mathrm{~min}$, we analyzed the mixture and found that nitrosobenzene was converted completely with an aniline selectivity of $76.2 \%$ (Table 4 , entry 5). The other product was main azoxybenzene, which was formed from the reaction between nitrosobenzene and hy-

Table 4

Reduction of some possible intermediates.

\begin{tabular}{lcccc}
\hline Entry & Substrate & Product & $X$ (Nitrobenzene) $/ \%$ & $S / \%$ \\
\hline 1 & AXB & HAB & 100 & 93.2 \\
2 & AB & HAB & 94.4 & 100 \\
$3^{\text {a }}$ & AB & HAB & 36.0 & 100 \\
$4^{\mathrm{b}}$ & HAB & HAB & 0 & 101.1 \\
$5^{\mathrm{b}}$ & $\mathrm{NSB}$ & Aniline & 100 & 76.2 \\
$6^{\mathrm{a}, \mathrm{b}}$ & $\mathrm{NSB}$ & Aniline & 100 & 73.5 \\
$7^{\mathrm{a}, \mathrm{c}}$ & $\mathrm{NSB}$ & Aniline & 100 & 97.9 \\
$8^{\mathrm{d}}$ & $\mathrm{HDA}$ & Aniline & 53.9 & 95.6 \\
\hline
\end{tabular}

Reaction conditions: $20 \mathrm{mg}$ of oCNT, $0.3 \mathrm{~g}$ of substrate, $3.5 \mathrm{~mL}$ of hydrazine, $100^{\circ} \mathrm{C}, 4 \mathrm{~h}$.

a No catalyst. ${ }^{b}$ Reacted for $1 \mathrm{~min} .{ }^{\mathrm{c}}$ Room temperature, and $5 \mathrm{~mL}$ of ethanol was used as solvent. After hydrazine was added, the mixture was detected immediately. ${ }^{d}$ Reacted for $1 \mathrm{~h}$. HAB-Hydrazobenzene. HDA-Hydroxylamine. droxylamine (hydroxylamine was derived from the reduction of nitrosobenzene). Even when no catalyst was used, the reduction of nitrosobenzene was still as fast as with oCNT (Table 4, entry 6). When nitrosobenzene was first dissolved in ethanol at room temperature and then hydrazine monohydrate was added to the solution, a violent reaction was also observed. The mixture was analyzed immediately and no nitrosobenzene was found (Table 4, entry 7). Surprisingly, the aniline selectivity increased to $97.9 \%$, suggesting that the reduction of nitrosobenzene readily proceeded in a non-catalytic homogeneous phase. Finally, hydroxylamine was used as substrate. After $1 \mathrm{~h}$, only $53.9 \%$ of conversion was obtained, and the product was also primarily aniline (Table 4 , entry 8 ).

From these results, we concluded that the direct pathway rather than the condensation one was more likely for nitrobenzene reduction catalyzed by a carbon material when hydrazine monohydrate was used as reductant. Moreover, nitrosobenzene can be quickly and directly converted to aniline even at room temperature without a catalyst.

\subsection{Role of the different oxygenated groups}

A nitric acid treatment can remove exposed Fe impurities as well as introduce oxygenated groups on the carbon surface. After nitric acid oxidation, the obtained oCNT performed better than rCNT (Table 5, entries 7 and 8), indicating that oxygen functional groups on the carbon surface instead of Fe impurities were important. In order to study the role of the different functional groups, we treated oCNT at various temperatures under a noble gas because these groups are decomposed at different temperatures depending on their identity [26,27].

The TGA results (Fig. 3(a)) showed that the weight loss of oCNT reached $5.6 \%$ when the temperature reached $900{ }^{\circ} \mathrm{C}$, while that for oCNT-800 was only $1.1 \%$, indicating that a large amount of functionalities can be eliminated by the thermal treatment. However, these functional groups can be anchored on the surface again by reoxidation of the annealed sample. The TPD results (Fig. 3(b)) revealed that the carboxylic group can be removed at $300{ }^{\circ} \mathrm{C}$, while anhydride was eliminated at 500 ${ }^{\circ} \mathrm{C}$. In comparison, the lactone, ether and hydroxyl groups were stripped at a relatively higher temperature $\left(700^{\circ} \mathrm{C}\right)$. The carbonyl group was the most stable, but after a thermal treatment at $800{ }^{\circ} \mathrm{C}$, a large portion of this functionality was also removed.

Table 5

Performance of the different CNT samples.

\begin{tabular}{lccc}
\hline Entry & Catalyst & $X$ (Nitrobenzene)/\% & $S($ Aniline $) / \%$ \\
\hline 1 & oCNT & 33.9 & 98.8 \\
2 & oCNT-300 & 73.5 & 92.4 \\
3 & oCNT-500 & 81.4 & 92.5 \\
4 & oCNT-700 & 51.4 & 94.6 \\
$5^{\text {a }}$ & oCNT-800 & 35.7 & 98.8 \\
$6^{\text {a }}$ & rCNT-800 & 27.6 & 99.1 \\
$7^{\text {a }}$ & rCNT & 43.2 & 99.4 \\
$8^{\text {a }}$ & oCNT & 63.0 & 95.5 \\
\hline
\end{tabular}

Reaction conditions: $20 \mathrm{mg}$ of catalyst, $1.2 \mathrm{~g}$ of nitrobenzene, 6.0 equivalent of hydrazine monohydrate, $80^{\circ} \mathrm{C}, 4 \mathrm{~h}$.

a Reacted at $90^{\circ} \mathrm{C}$. 

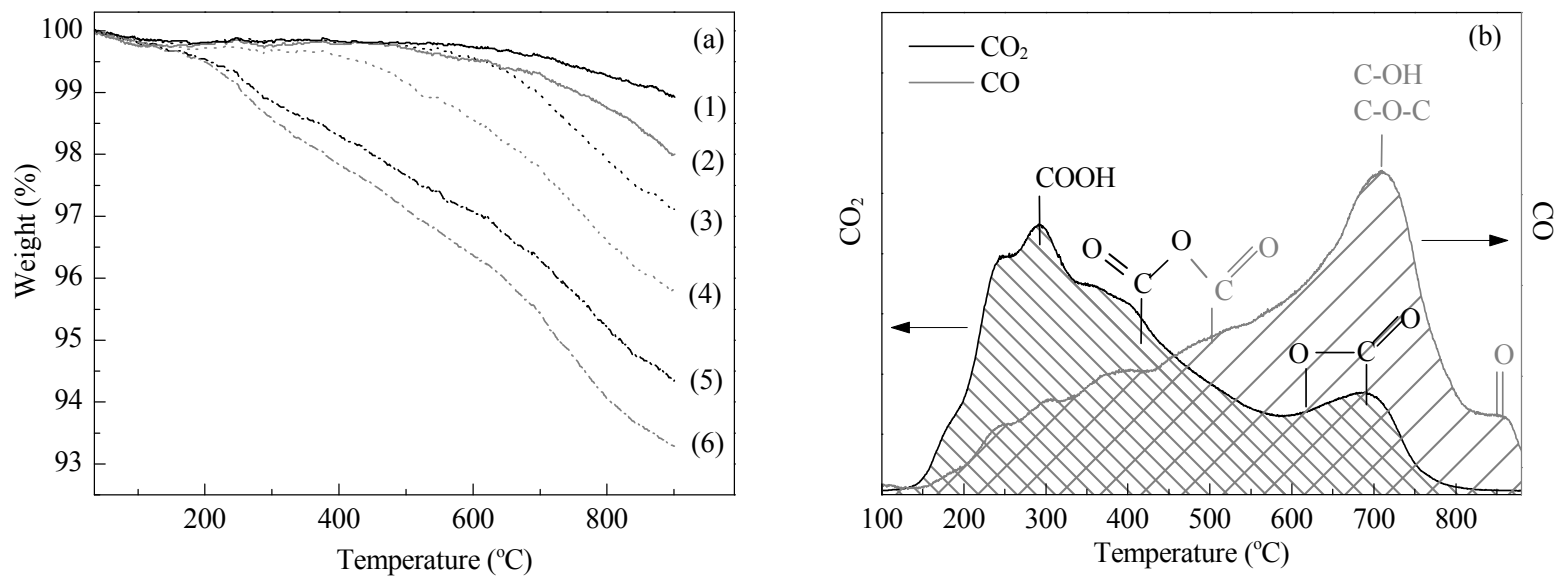

Fig. 3. TGA curves of CNT samples (a) and TPD profiles of oCNT (b) [28]. (1) oCNT-800; (2) oCNT-700; (3) oCNT-500; (4) oCNT-300; (5) oCNT; (6) o-oCNT800 obtained by reoxidation of oCNT-800 with concentrated nitric acid.

After the carboxylic group was removed, the activity was improved compared to oCNT (Table 5, entries 1 and 2), although the aniline selectivity was decreased slightly, suggesting that the carboxylic group had an adverse effect. This was because the carboxylic groups increased the hydrophilicity of the carbon catalyst but nitrobenzene is a hydrophobic reagent. As a result, the existence of carboxylic groups hindered the adsorption of nitrobenzene. A further increase in activity can be observed when anhydride was eliminated (Table 5, entry 3), revealing that anhydride also played an adverse role because it was hydrolyzed to a carboxylic group in the reaction. The lactone, ether and hydroxyl groups were decomposed when oCNT was annealed at $700{ }^{\circ} \mathrm{C}$, and there was a notable deactivation for oCNT-700 compared to oCNT-500 (Table 5, entries 3 and 4), indicating that some of these three functionalities play a positive role. However, it was difficult to distinguish the contribution of each functional group. An obvious deactivation was observed after oCNT was calcined at $800{ }^{\circ} \mathrm{C}$ during which a large portion of the carbonyl groups were stripped. As Fe impurities cannot be removed by the thermal treatment under these conditions, the decreased activity would be due to the removal of these oxygenated groups, especially the carbonyl group.

\subsection{Other factors responsible for activity}

Since certain oxygen species played a key role as discussed above, another question is: are other properties of the carbon catalyst important to the reaction? Or did the nitric acid oxidation and thermal treatment have some other side effect, such as increasing the surface area of the material or exposing new active sites?

In order to answer this question, we firstly analyzed these samples by TEM. There was some amorphous carbon on the surface of these samples, but almost no change of morphology was observed after the nitric acid oxidation and subsequent thermal treatment (Fig. 4). So the effect of morphology on the reaction can be ruled out.

We further studied the textural properties of these catalysts by $\mathrm{N}_{2}$ adsorption. All the samples gave a clear hysteresis at a high relative pressure, and gave Type IV isotherms (not shown). Apart from isotherm type, these samples showed a similar pore size distribution as well as total pore volume (Table 6).

One notable change was the specific surface area, which was often an important factor in catalysis. After nitric acid oxidation, the surface area was increased compared to rCNT. The surface area was further gradually increased as the annealing temperature was elevated. However, there was no relationship between the surface area and activity, and it was unlikely that
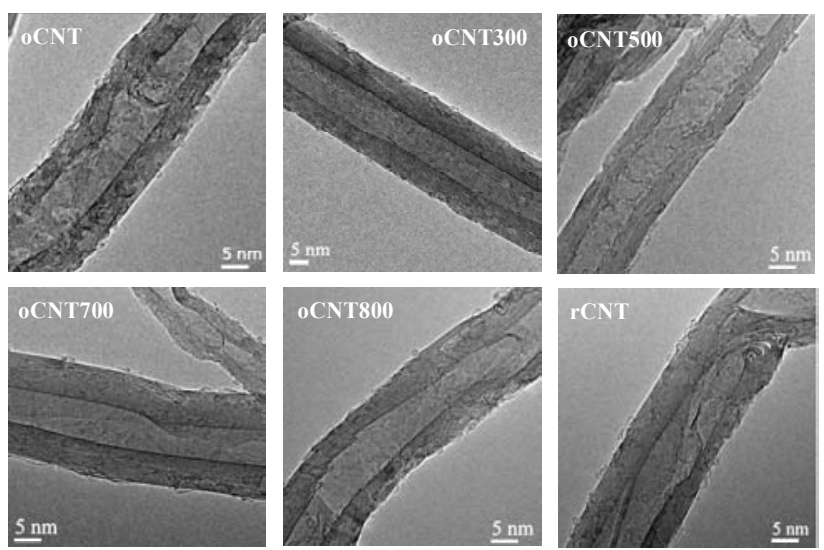

Fig. 4. TEM images of the different samples.

Table 6

Some textural properties of the CNT samples.

\begin{tabular}{lcccc}
\hline Catalyst & $A_{\text {BET }^{\mathrm{a}} /\left(\mathrm{m}^{2} / \mathrm{g}\right)}$ & $A_{\text {micro }} \mathrm{b} /\left(\mathrm{m}^{2} / \mathrm{g}\right)$ & $V_{t}^{\mathrm{c}}$ & $D^{\mathrm{d}} / \mathrm{nm}$ \\
\hline oCNT & 231.5 & 8.6 & 1.52 & 32.3 \\
oCNT-300 & 236.9 & 5.1 & 1.55 & 33.0 \\
oCNT-500 & 255.5 & 10.0 & 1.50 & 33.1 \\
oCNT-700 & 261.4 & 8.2 & 1.40 & 31.8 \\
oCNT-800 & 266.2 & 8.5 & 1.69 & 34.5 \\
rCNT & 212.2 & 3.1 & 1.65 & 31.2 \\
rCNT-800 & 312.8 & 5.2 & 1.66 & 34.1 \\
\hline
\end{tabular}

${ }^{a}$ BET surface area. ${ }^{b}$ Micropore area. ${ }^{c}$ Total pore volume. ${ }^{d}$ Pore diameter at the maxima of pore size distribution curves. 
the high surface area gave the good catalytic performance. Although oCNT-800 had the highest surface area, it provided the lowest activity because most of the active oxygen groups were removed. These results demonstrated that the specific surface area itself had a negligible effect on the reaction.

Raman spectroscopy is widely used for the characterization of carbon materials, especially nanocarbon. The Raman spectra of the CNT catalysts were divided into four Lorentzian peaks and one Gaussian peak (Fig. 5) following the procedure of Sadezky et al [29]. The D band located at $1320 \mathrm{~cm}^{-1}$ resulted from structural defects on the graphitic planes of the carbon nanotube, while the $\mathrm{G}$ band centered at $1571 \mathrm{~cm}^{-1}$ was due to the graphitic structure. The $I_{D} / I_{G}$ ratio is an indication of the number of structural defects and is a quantitative measure of the exposed edge plane. The $\mathrm{I}_{\mathrm{D}} / \mathrm{I}_{\mathrm{G}}$ ratio was calculated to be 2.51 for rCNT, and 2.48 for oCNT, indicating that the oxidation treatment under the present conditions did not increase the number of defects, which was in accordance with a previous report [30]. Since oCNT performed better than rCNT (Table 5, entries 7 and 8), the result indicated that the activity mainly originated from certain oxygenated groups rather than structural defects, that is, the improved performance was due to the introduction of active oxygenated functional groups. As a matter of fact, the performance of rCNT was also due to active oxygenated groups because when rCNT was annealed at $800{ }^{\circ} \mathrm{C}$, notable deactivation was observed for rCNT-800 (Table 5, entry 6) although the ID/IG ratio was slightly increased (2.65 and 2.73 for oCNT-800 and rCNT-800, respectively).

\subsection{Performance of other carbon materials}

The nanodiamond (UDD) sample was synthesized by the detonation method followed by washing with perchloric acid. As a result, there are abundant oxygen functional groups on its surface. However, UDD exhibited rather low activity in the tested reaction (Table 7 , entry 1 ). This could be due to the fact that UDD is a $\mathrm{sp}^{3}$ hybridized material which does not have a conjugated $\pi$ system (Fig. 6(a)). The absence of a conjugated $\pi$ system will hamper electron transfer and the adsorption of nitrobenzene, which are important factors for the carbon-catalyzed reduction of nitrobenzene [31].

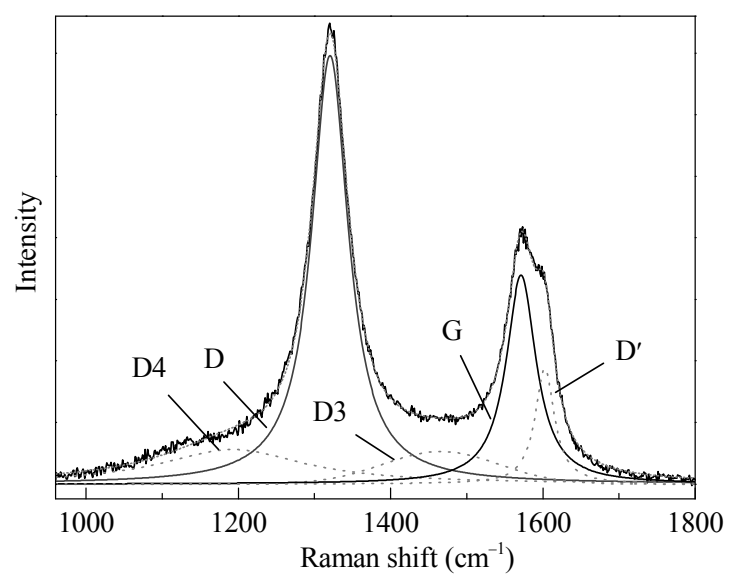

Fig. 5. Raman spectra of the CNT sample.
Table 7

Performance of other carbon materials.

\begin{tabular}{lccc}
\hline Entry & Catalyst & $X$ (Nitrobenzene) $\%$ & $S($ Aniline $) / \%$ \\
\hline 1 & UDD & 21.1 & 100 \\
2 & UDD-1300 & 42.8 & 97.3 \\
$3^{\text {a }}$ & UDD-1300 & 95.8 & 94.4 \\
4 & Graphite & 37.7 & 96.1 \\
5 & GO-t & 73.6 & 98.2 \\
6 & RGO & 90.4 & 98.0 \\
7 & G-300 & 90.1 & 95.3 \\
8 & G-800 & 59.3 & 99.1 \\
9 & AC & 62.5 & 98.2 \\
10 & oAC & 77.2 & 96.8 \\
11 & oAC-800 & 42.1 & 97.7 \\
\hline
\end{tabular}

conditions: $20 \mathrm{mg}$ of catalyst, $1.2 \mathrm{~g}$ of nitrobenzene, 6.0 equivalent of hydrazine monohydrate, $100^{\circ} \mathrm{C}, 4 \mathrm{~h}$.

a UDD-1300 was treated with $3 \mathrm{~mL}$ of $10 \% \mathrm{H}_{2} \mathrm{O}_{2}$ at $100{ }^{\circ} \mathrm{C}$ for $2 \mathrm{~h}$.

b GO-t was obtained by reduction of GO with hydrazine monohydrate, but GO was not dispersed by ultrasonification before reduction.

c $\mathrm{G}-300$ was prepared by thermal reduction of G0 under an inert gas flow at $300{ }^{\circ} \mathrm{C}$, while G-800 was fabricated at $800^{\circ} \mathrm{C}$.

After a thermal treatment at $1300{ }^{\circ} \mathrm{C}, \mathrm{sp}^{2}$ surface overlayers were formed on UDD (Fig. 6(b)). In agreement with our hypothesis, the activity of the treated sample (UDD-1300) was improved, although the conversion was still low (Table 7, entry 2) because most of the active oxygen species were eliminated at this high temperature. In order to test whether oxygenated groups were also important for UDD-based materials, we oxidized UDD-1300 with $\mathrm{H}_{2} \mathrm{O}_{2}$. As expected, the performance became much better (Table 7, entry 3). These results further confirmed the vital role of oxygen functionalities. In addition, the conjugated $\pi$ system was also important in this reaction.

Graphene-based materials have attracted increasing attention and are already effective catalysts in chemical reactions $[15,17,20]$. Graphite $\left(10.8 \mathrm{~m}^{2} / \mathrm{g}\right)$, which is one of the most widely used raw materials for the preparation of graphene, showed some activity in nitrobenzene reduction (Table 7, entry 4). After oxidation by Hummers method, GO was obtained, which has abundant oxygen-containing groups. Because a large part of the oxygenated groups on GO would be removed by hydrazine, we pretreated GO with hydrazine under a condition similar to the reaction. Considering that the GO catalyst was not dispersed by ultrasonification, the obtained GO-t $\left(41.2 \mathrm{~m}^{2} / \mathrm{g}\right)$ which demonstrated improved performance was probably reduced graphite oxide and not the so-called RGO. In comparison, RGO (654.9 m²/g), which was prepared by efficiently dis-
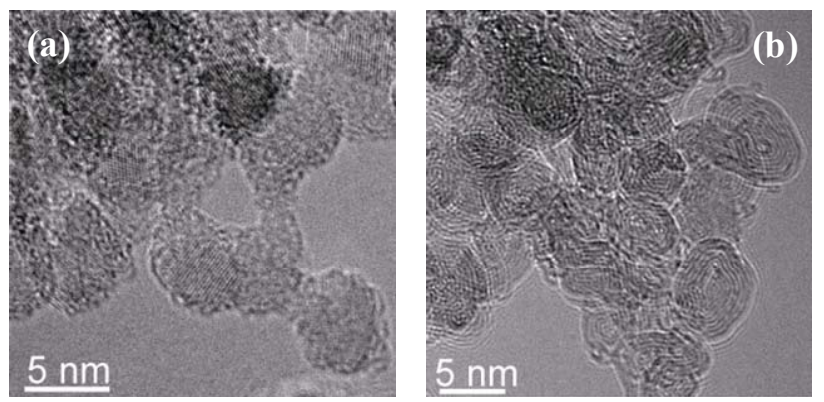

Fig. 6. TEM images of UDD (a) and the sample obtained by graphitization of UDD at $1300^{\circ} \mathrm{C}(\mathrm{b})$. 

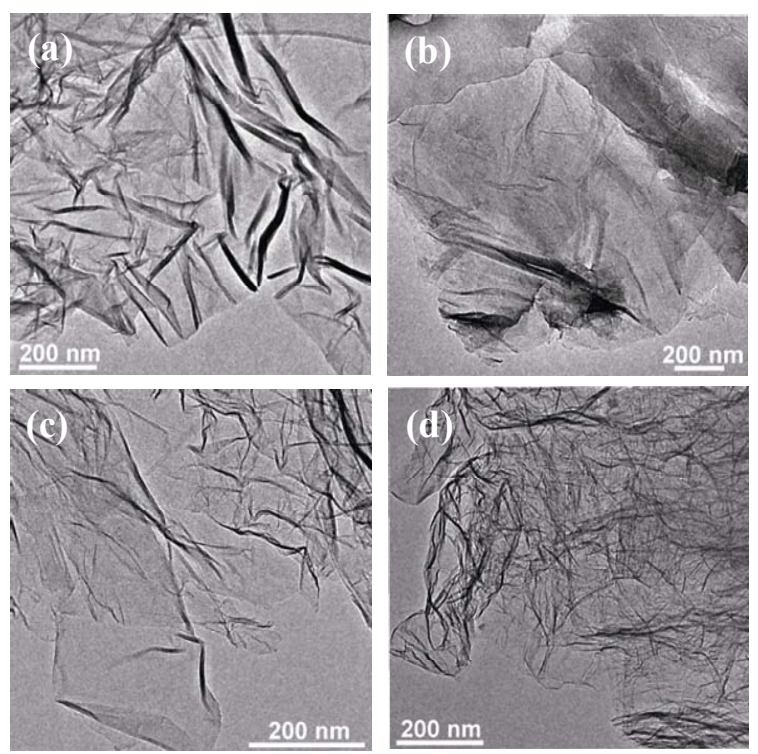

Fig. 7. TEM images of graphene related materials. (a) RGO; (b) GO-t; (c) G-300; (d) G-800.

persing GO by ultrasonication and subsequent hydrazine reduction, exhibited the best activity among the three catalysts. Although a large amount of the functional groups on the surface of RGO were removed by hydrazine, still a large portion of oxygenated species remained as previously reported [32]. The XPS results showed that about $9 \%$ of the oxygen remained after hydrazine reduction (not shown), and these oxygenated functionalities would play an important role in the reaction. The obviously larger surface area of RGO would expose more active oxygen species than GO-t. In addition, the larger exposed $\mathrm{sp}^{2}$ graphene layers of RGO would be more favourable for the adsorption of the reactant.

$\mathrm{G}-300$ was obtained by the thermal reduction $\left(300^{\circ} \mathrm{C}\right)$ of GO under an inert gas flow (Fig. 7). This catalyst exhibited a similar activity to that of RGO (Table 7, entries 6 and 7). Notable deactivation was observed when the thermal reduction of GO was carried out at $800{ }^{\circ} \mathrm{C}$ (Table 7, entry 8), which would be caused by the removal of a large portion of the active oxygenated func- tional groups.

Activated carbon (AC) possessed a quite high surface area, but exhibited a relatively low performance compared to the CNTs and graphene materials. However, the results also confirmed the importance of the oxygen functionalities. After oxidation with nitric acid, the obtained oAC performed better than $\mathrm{AC}$, which was followed by an obvious deactivation when oAC was treated at $800{ }^{\circ} \mathrm{C}$ because most of the active oxygenated functional groups were eliminated (Table 7, entries 9-11).

\section{Conclusions}

Carbon materials are an efficient catalyst for nitrobenzene reduction using hydrazine monohydrate as the reducing reagent. The catalyst loading, reaction temperature and solvent influenced the reaction. TGA, TPD, $\mathrm{N}_{2}$ adsorption, TEM and Raman analysis in combination with catalytic tests suggested that the activity was due to oxygenated groups and not to structural defects or Fe impurities. Of the different oxygenated species, the carbonyl group was critical for activity, while carboxylic group and anhydride were adverse for the reaction. In addition, a conjugated $\pi$ system also played an important role because it is necessary for electron transfer and the adsorption of nitrobenzene. The reaction proceeded through the direct route in which nitrosobenzene was convert directly to aniline quickly without a catalyst. These findings are useful for the study of the carbon catalyzed reactions and for designing carbon catalysts.

\section{References}

[1] Downing R S, Kunkeler P J, van Bekkum H. Catal Today, 1997, 37: 121

[2] Wegener G, Brandt M, Duda L, Hofmann J, Klesczewski B, Koch D, Kumpf R J, Orzesek H, Pirkl H G, Six C, Steinlein C, Weisbeck M. Appl Catal A, 2001, 221: 303

[3] Nomura K. J Mol Catal A, 1998, 130: 1

[4] Corma A, Serna P. Science, 2006, 313: 332

[5] Gelder E A, Jackson S D, Lok C M. Catal Lett, 2002, 84: 205

[6] Zhang J L, Wang Y, Ji H, Wei Y G, Wu N Z, Zuo B J, Wang Q L. J Catal,

\section{Graphical Abstract}

Chin. J. Catal., 2014, 35: 914-921 doi: 10.1016/S1872-2067(14)60102-9

\section{Reduction of nitrobenzene catalyzed by carbon materials}

Shuchang Wu, Guodong Wen, Bingwei Zhong, Bingsen Zhang, Xianmo Gu, Ning Wang, Dangsheng Su* Institute of Metal Research, Chinese Academy of Sciences; Graduate University of Chinese Academy of Sciences; The Hong Kong University of Science and Technology

Carbon was an efficient catalyst for nitrobenzene reduction. The carbonyl group played an important role, while the carboxylic group and anhydride adversely affected the reaction.

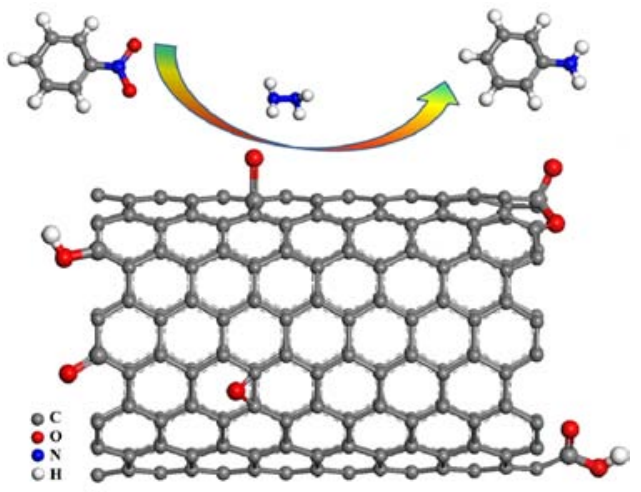


2005, 229: 114

[7] Ragaini F, Cenini S. J Mol Catal A, 1996, 105: 145

[8] Jagadeesh R V, Wienhöfer G, Westerhaus F A, Surkus A E, Pohl M M, Junge H, Junge K, Beller M. Chem Commun, 2011, 47: 10972.

[9] Kim S-S, Kim E-S, Kim B M. Chem-Asia J, 2011, 6: 1921

[10] Lin W W, Cheng H Y, Ming J, Yu Y C, Zhao F Y. J Catal, 2012, 291: 149

[11] Patra A K, Dutta A, Bhaumik A. Catal Commun, 2010, 11: 651

[12] Zhang J, Liu X, Blume R, Zhang A H, Schlögl R, Su D S. Science, 2008, 322: 73

[13] Frank B, Zhang J, Blume R, Schlögl R, Su D S. Angew Chem Int Ed, 2009, 48: 6913

[14] Kuang Y, Islam N M, Nabae Y, Hayakawa T, Kakimoto M. Angew Chem Int Ed, 2010, 49: 436

[15] Dreyer D R, Jia H P, Bielawski C W. Angew Chem Int Ed, 2010, 49: 6813

[16] Yu H, Peng F, Tan J, Hu X W, Wang H J, Yang J, Zheng W X. Angew Chem Int Ed, 2010, 50: 3978

[17] Huang H, Huang J, Liu Y M, He H Y, Cao Y, Fan K N. Green Chem, 2012, 14: 930

[18] Li B J, Xu Z.J Am Chem Soc, 2009, 131: 16380

[19] Han B H, Dea H S, Sung Y C. Tetrahedron Lett, 1985, 26: 6233

[20] Gao Y J, Ma D, Wang C L, Guan J, Bao X H. Chem Commun, 2011, 47: 2432
[21] Zhou H Y, Shi L, Sun Q. Chin J Catal (周宏跃, 石雷, 孙琪. 催化学 报), 2012, 33: 1463

[22] Wu S C, Wen G D, Liu X M, Zhong B W, Su D S. ChemCatChem, DOI: 10.1002/cctc. 201402070

[23] Hummers W S, Offeman R E.J Am Chem Soc, 1958, 80: 1339

[24] Li D, Müller M B, Gilje S, Kaner R B, Wallace G G. Nat Nanotechnol, 2008, 3: 101

[25] Corma A, Concepción P, Serna P. Angew Chem Int Ed, 2007, 46: 7266

[26] Okpalugo T I T, Papakonstantinou P, Murphy H, McLaughlin J, Brown N M D. Carbon, 2005, 43: 153

[27] Figueiredo J L, Pereira M F R, Freitas M M A, Órfão J J M. Carbon, 1999, 37: 1379

[28] Zhong B W, Liu H Y, Gu X M, Su D S. ChemCatChem, DOI: 10.1002/cctc. 201400082

[29] Sadezky A, Muckenhuber H, Grothe H, Niessner R, Pöschl U. Carbon, 2005, 43: 1731

[30] Tessonnier J P, Rosenthal D, Hansen T W, Hess C, Schuster M E, Blume R, Girgsdies F, Pfänder N, Timpe O, Su D S, Schlögl R. Carbon, 2009, 47: 1779

[31] Larsen J W, Freund M, Kim K Y, Sidovar M, Stuart J L. Carbon, 2000, 38: 655

[32] Ambrosi A, Chua C K, Bonanni A, Pumera M. Chem Mater, 2012, 24: 2292

\title{
碳材料催化硝基苯还原反应
}

\author{
吴树昌 ${ }^{\mathrm{a}, \mathrm{b}}$, 温国栋 ${ }^{\mathrm{a}}$, 钟炳伟 ${ }^{\mathrm{a}}$, 张炳森 ${ }^{\mathrm{a}}$, 谷献模 ${ }^{\mathrm{a}}$ ，王 宁 ${ }^{\mathrm{c}}$, 苏党生 ${ }^{\mathrm{a},{ }^{*}}$ \\ ${ }^{a}$ 中国科学院金属研究所沈阳材料科学国家(联合) 实验室, 辽宁沈阳 110016 \\ b 中国科学院大学, 北京 100049 \\ c香港科技大学物理系, 香港
}

摘要: 本文对碳材料(主要是碳纳米管)催化硝基苯的还原反应进行了系统研究. 通过热重分析、程序升温脱附、透射电子显微镜、 物理吸附以及拉曼光谱等表征, 发现碳材料表面的含氧官能团在反应中起着重要的作用, 而比表面、孔结构、形貌、结构缺陷以 及可能存在的铁杂质对反应没有显著影响. 羰基的作用非常重要, 但是羧基和酸䣲对反应不利. 除此之外, 材料的 $\pi$ 电子体系也很 关键, 因为它可以传递电子, 并且利于硝基苯的吸附. 硝基苯还原按照直接路径进行, 反应过程中生成的中间体亚硝基苯可以迅 速转化为苯胺.

关键词: 碳材料; 氧官能团; 活性位; 硝基苯; 还原

收稿日期: 2014-03-15. 接受日期: 2014-03-27. 出版日期: 2014-06-20.

*通讯联系人. 电话: (024) 23971577; 传真: (024) 83970019; 电子信箱: dssu@imr.ac.cn

基金来源：国家重点基础研究发展计划(973计划，2011CBA00504); 国家自然科学基金(21133010, 51221264, 21261160487, 21203215); 中国科学院战略先导项目(XDA09030103); 辽宁省博士启动基金(20121068).

本文的英文电子版由Elsevier出版社在ScienceDirect上出版(http://www.sciencedirect.com/science/journal/18722067). 